Article

\title{
Varying Levels of Genetic Control and Phenotypic Plasticity in Timing of Bud Burst, Flower Opening, Leaf Senescence and Leaf Fall in Two Common Gardens of Prunus padus L.
}

\author{
Kristine Vander Mijnsbrugge *(D) and Stefaan Moreels \\ Department of Forest Ecology and Management, Research Institute for Nature and Forest, \\ B-9500 Geraardsbergen, Belgium; stefaan.moreels@inbo.be \\ * Correspondence: kristine.vandermijnsbrugge@inbo.be; Tel.: +32-47-828-2137
}

Received: 30 August 2020; Accepted: 1 October 2020; Published: 6 October 2020

check for updates

\begin{abstract}
Several phenological phases mark the seasonal growth pattern in temperate woody perennials. To gain further insight into the way these phases react on an altering growth environment, we tested whether vegetative and reproductive phenophases in a shrub species respond differentially among different genetic entities and between two different planting sites. We scored leaf bud burst, flower opening, leaf senescence and leaf fall on 267 ramets of Prunus padus L. belonging to 53 genotypes that were sampled in 9 local populations, and that were planted in 2 common gardens in the northern part of Belgium. The data were processed with cumulative logistic regression. The contribution of genetic and non-genetic components to the total variability varied between the four studied seasonal phenophases. The timing of flower opening displayed the smallest relative amount of intragenotypic variance (between ramets), suggesting a stronger genetic control and a lesser need at the individual plant level for plastic fine tuning to the micro-environment. In addition, whereas leaf bud burst showed the highest relative variance at the interpopulation level among all phenophases, probably at least partly attributable to local adaptation, flower opening displayed the highest intergenotypic variance, which may have been promoted more by assortative mating. Spring phenophases were strongly correlated $(r=0.89)$ as well as the autumnal phenophases $(r=0.72)$. Flower opening was not correlated with the autumnal phenophases. Timing of leaf bud burst and leaf senescence were negatively correlated, demonstrating that the length of the growing season enlarged or diminished among the studied genotypes. Although the two planting sites were only $24 \mathrm{~km}$ apart, all phenophases were advanced at the less exposed site, indicating a phenotypic plastic response. Together, our results suggest that in P. padus, flowering is less sensitive to environmental variation than leaf bud break and may show a lesser impact of a changing environment on this reproductive phenophase.
\end{abstract}

Keywords: Prunus padus L.; bud burst; leaf senescence; leaf shedding; common garden; variance partitioning; local adaptation; assortative mating; phenotypic plasticity; cumulative logistic regression

\section{Introduction}

Understanding how plants respond to environmental change will help predict the impact of climate change on plant populations. This is especially true for woody species that are sessile and perennial organisms, have a long life-span, support diverse communities and give structure to a wide range of ecosystems on Earth [1]. An individual plant can maintain its fitness by altering its phenotype in response to a changing growth environment [2]. Trees experience considerable variation in growth conditions throughout their life [3,4]. Therefore, the ability of tree species for phenotypic plastic responses and to adapt locally to altering environments is studied [5]. Plasticity will likely play an 
important role in the short term, but may become insufficient when local climates change to conditions outside the range of historical variability that populations have encountered before, whereas trees may harbor capacities for quick adaptation to environmental changes [6]. This capacity is dependent on the genetic variation in tree populations [6]. An easy way to study genetic variation within and among tree populations is by means of common garden experiments, where individuals from different genetic entities grow in the same environment, and, thus, any average difference in a trait between the genetic entities must have a genetic origin [7]. In this way, the genetic basis of phenotypic variation can be unraveled, without the interfering effects of the growth environment. Using quantitative genetics, complex traits such as life history, morphological and physiological traits, phenology and allometric relationships can be studied [7]. The distribution of genetic variation for fitness related traits, including the genetic differentiation between populations, is commonly studied in open pollinated progenies planted in common gardens [8].

The phenophases signposting the timing and the duration of crucial turning points of seasonal growth in woody plants are adaptive in nature, varying among populations [8]. Environmental change induces selection in these traits [9]. The seasonal cycle of leaves of deciduous temperate tree species consists in essence of the timing of bud burst in spring and the timing of bud formation, leaf senescence and leaf shedding in autumn. These timings maximize the annual growth whilst minimizing the risk of frost damage. Frost damage in trees is associated with high fitness costs [10]. In spring, late frosts can cause harm to the soft tissues of emerging leaves, whereas in autumn, early frosts may hamper the resorption of nitrogen and other nutrients because of an advanced leaf abscission.

Leaf bud burst in spring varies considerably among tree species and responds to altering climatic conditions [6,8]. Spatially variable selection on timing of bud burst can be strong enough to neutralize the homogenizing effect of gene flow [11]. Therefore, population differentiation for bud burst in trees, as detected in common gardens, typically follows clines in temperature at the home sites of the populations [8,12]. Several studies demonstrated high heritability values for the timing of bud burst in trees [13-15]. Common garden studies generally use populations originating from diverse latitudes or altitudes, whereas studies on genetic patterns of variation within and among populations at the local scale are limited. A detailed study in Denmark on population differentiation using bud burst data in six perennial species, including the insect pollinated Cornus sanguinea L., Malus sylvestris (L.) Mill. and Rosa dumalis (Bechst) Boulay, demonstrated significant differentiation among local populations that were in some cases separated only by 10 to $35 \mathrm{~km} \mathrm{[16].} \mathrm{It} \mathrm{was} \mathrm{suggested}$ that this differentiation in the insect-pollinated species resulted from natural selection and neutral processes acting simultaneously [16]. Similarly, population differentiation on a local scale was found among isolated populations of Tilia cordata Mill., an insect-pollinated tree species, in Denmark [17]. Additionally, here, a combination of genetic drift and divergent selection was expected to play significant roles in the observed genetic pattern [17].

The timing of flower opening is related to reproduction and fecundity. In general, it is influenced by water limitation, which has variable effects, and by herbivory which consistently delays flowering [18]. Similar as for leaf bud burst, high heritability values are found for timing of flowering in general [19]. Divergent timing of flowering can give rise to assortative mating (early flowering plants pollinate other early plants; late plants pollinate late plants), which reduces gene flow and promotes differentiation [18]. The timing of flowering varies among woody angiosperm species and can occur before, during or after bud burst. The timing of bud burst and the timing of flowering at the tree level are most likely auto-correlated $[14,20]$ in the sense that early flushing trees flower early and the same for late flushing trees, although this is not always the case [21].

The timing of the autumnal phenophases is at least partly determined by the need for appropriate nutrient resorption as the emergence of new foliage in the following spring relies greatly on nutrients resorbed in the preceding autumn [22]. In comparison with leaf bud burst, the timing of leaf senescence shows less year-to-year variability and is associated with less favorable conditions for photosynthesis [23]. While the timing of bud burst is mainly influenced by temperature [24,25], 
autumnal leaf senescence is responding both to photoperiod and to temperature [23]. Still, there is no consensus on the exact factors that control leaf senescence [23]. Leaf fall is the next phenophase following leaf senescence. Similar to the spring phenophases bud burst and flowering, and more so as it concerns the same vegetative organ, the timing of leaf senescence and leaf abscission is most likely strongly auto-correlated. This auto-correlation is reported to be to such an extent that leaf fall can be used as a proxy for leaf senescence, taking into account a certain delay in time [26].

The quantitative genetic knowledge of lesser known or rare forest tree and shrub species remains scarce. We focused on Prunus padus L. (European bird cherry), which has a wide natural distribution area in Europe [27]. The species usually forms small populations in the undergrowth of riparian and moist forests [28]. Shrubby thickets are common in meadows. Furthermore, P. padus creates blooming edgings of forests. The species is insect pollinated and is characterized by endozoic dispersal [28]. Birds are essential disseminating agents. Fruits that fall beneath the shrubs may be dispersed by small mammals. To address the question how the shrub P. padus may respond to a changing environment, we combined two advantages related to this species. One is that it takes less time to achieve a reproductive life stage in comparison to tree species. Secondly, P. padus can easily be propagated vegetatively through cuttings, allowing an additional hierarchical level of relatedness among the individuals planted in a common garden, namely, the clonal level (further called ramets) next to the individual level (genotypes) and the populations. Planting of identical genotypes in clonal repetitions permits a detailed analysis of variance, accounting for both within genotype variation (non-genetic) and variation between genotypes and populations (genetic). Traditionally, half-sib offspring of mother trees, called families, are planted in common gardens of tree species. We adopted a more stringent method, making use of vegetatively propagated plants planted in two common gardens. We firstly hypothesized different levels of genetic control for the four phenophases leaf bud burst, flower opening, leaf senescence and leaf fall when compared with each other. Secondly, we questioned whether different responses could be detected for the four phenophases of clonal replicates at the two plantation sites, which indicates phenotypic plasticity. It should be noted that we focused on the relative differences between the four phenophases without any intention to model the absolute timing of the phenophases. The latter needs a different analysis including chilling and forcing temperatures and will be subject of another study.

\section{Materials and Methods}

\subsection{Source Material and Planting Sites}

Cuttings were taken in the spring of 2006 for the clonal propagation of 53 genotypes sampled in 9 local natural populations in the northern part of Belgium (Figure 1, Table 1). These populations were classified as autochthonous in an inventory locating sites harbouring autochthonous populations of trees and shrubs in the northern part of Belgium [29]. As P. padus is known to propagate vegetatively by natural root suckers, sampling from the same genotype was avoided by evaluating the distance between two shrubs (at least $5 \mathrm{~m}$ without any P. padus shrub in between two sampled shrubs), and by evaluating differences in the habitus of the shrubs. Vigorously growing shoots (the season's new growth) on the mother shrubs in the natural populations were cut and taken to the greenhouse. There, shoots were cut with a grafting knife in pieces of 6 to $7 \mathrm{~cm}$ length, still having at least one leaf. The cuttings' rooting edges were wounded by stripping of a small part of the bark. No phytohormones were applied as $P$. padus can propagate easily by cuttings. Cuttings were placed in trays filled with moist standard seeding and cutting soil, with the rooting edge $2 \mathrm{~cm}$ into the soil. Thin transparent plastic covered the cuttings until they rooted. Rooted cuttings were transferred to plant pots and grown to 267 two-year-old potted planting stock in the nursery of the Research Institute for Nature and Forest in Geraardsbergen, Belgium, following standard nursery methods. In Dentergem and in Semmerzake, 147 plants (53 genotypes, on average 2.8 ramets per genotype) and 120 plants (52 genotypes, on average 2.3 ramets per genotype) were planted, respectively. 
Table 1. Genotypes of Prunus padus L. that were sampled in natural populations in the northern part of Belgium and vegetatively propagated, and the number of ramets that were planted in the two common gardens at Dentergem $\left(\mathrm{n}_{\mathrm{D}}\right)$ and Semmerzake $\left(\mathrm{n}_{\mathrm{S}}\right)$.

\begin{tabular}{|c|c|c|c|}
\hline Population & Genotype & $\mathbf{n}_{\mathbf{D}}$ & $\mathbf{n}_{\mathrm{S}}$ \\
\hline \multirow[t]{7}{*}{ Brakel BR } & BR1 & 3 & 2 \\
\hline & BR2 & 3 & 3 \\
\hline & BR3 & 3 & 3 \\
\hline & BR4 & 3 & 2 \\
\hline & BR5 & 3 & 3 \\
\hline & BR6 & 2 & 3 \\
\hline & BR7 & 2 & 2 \\
\hline \multirow[t]{4}{*}{ Ename EN } & EN1 & 3 & 1 \\
\hline & EN2 & 2 & 1 \\
\hline & EN3 & 3 & 2 \\
\hline & EN4 & 3 & 3 \\
\hline \multirow[t]{4}{*}{ Herzele HER } & HER1 & 1 & 5 \\
\hline & HER2 & 2 & 4 \\
\hline & HER3 & 2 & 3 \\
\hline & HER4 & 1 & 2 \\
\hline \multirow[t]{4}{*}{ Krombeke KRO } & KRO1 & 4 & 1 \\
\hline & $\mathrm{KRO} 2$ & 4 & 2 \\
\hline & KRO3 & 3 & 2 \\
\hline & $\mathrm{KRO} 4$ & 4 & 2 \\
\hline \multirow[t]{4}{*}{ Merelbeke ME } & ME1 & 3 & 2 \\
\hline & ME2 & 2 & 2 \\
\hline & ME3 & 3 & 3 \\
\hline & ME4 & 2 & 2 \\
\hline \multirow[t]{6}{*}{ Poperinge PO } & PO1 & 3 & 2 \\
\hline & $\mathrm{PO} 2$ & 4 & 2 \\
\hline & PO3 & 4 & 2 \\
\hline & PO4 & 4 & 2 \\
\hline & PO5 & 4 & 1 \\
\hline & PO6 & 3 & 1 \\
\hline \multirow[t]{15}{*}{ Schorisse SC } & SC1 & 1 & 0 \\
\hline & SC2 & 2 & 2 \\
\hline & SC3 & 2 & 3 \\
\hline & SC4 & 3 & 1 \\
\hline & SC5 & 3 & 2 \\
\hline & SC6 & 3 & 2 \\
\hline & SC7 & 2 & 1 \\
\hline & SC8 & 3 & 3 \\
\hline & SC9 & 3 & 2 \\
\hline & SC10 & 3 & 2 \\
\hline & SC11 & 2 & 3 \\
\hline & SC12 & 2 & 3 \\
\hline & SC13 & 2 & 3 \\
\hline & SC14 & 2 & 3 \\
\hline & SC15 & 3 & 2 \\
\hline \multirow[t]{7}{*}{ Wijtschate WIJ } & WIJ1 & 3 & 3 \\
\hline & WIJ2 & 3 & 2 \\
\hline & WIJ3 & 3 & 3 \\
\hline & WIJ4 & 3 & 4 \\
\hline & WIJ5 & 4 & 1 \\
\hline & WIJ6 & 3 & 4 \\
\hline & WIJ7 & 3 & 2 \\
\hline \multirow[t]{2}{*}{ Zwalm ZW } & ZW1 & 3 & 2 \\
\hline & ZW2 & 3 & 2 \\
\hline
\end{tabular}




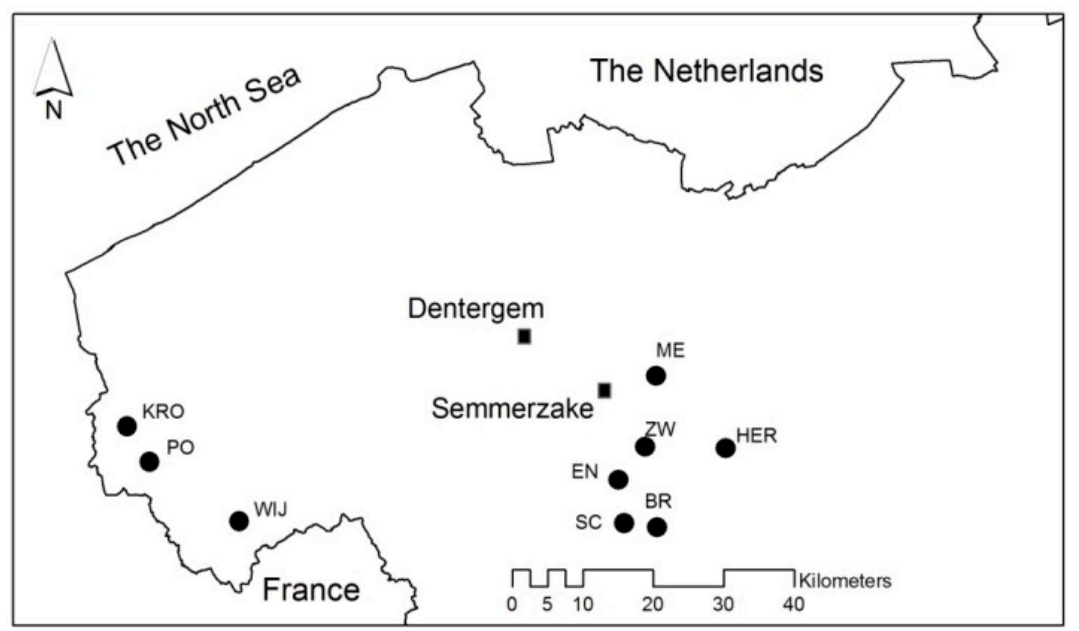

Figure 1. Map displaying the location of the nine natural populations of Prunus padus L. that were sampled (circles) and the location of the two common gardens Dentergem and Semmerzake (squares). Abbreviations of populations are in Table 1.

The two planting sites were $24 \mathrm{~km}$ apart from each other (Figure 1). For a modest approximation of the nutrient status of the soils at both sites, two random bulk soil samples were taken at each site from the Ah horizon of the mineral soil and dried at $40{ }^{\circ} \mathrm{C}(24 \mathrm{~h})$. Soil $\mathrm{pH}\left(\mathrm{H}_{2} \mathrm{O}\right)$ and electrical conductivity (EC) were measured at a 1:5 soil-to-water ratio. The site in Semmerzake (altitude of $7.5 \mathrm{~m}$ ) was alluvial and appeared nutrient richer ( $\mathrm{pH}$ values of 7.64 and 7.59; EC values of $127.6 \mu \mathrm{S} / \mathrm{cm}$ and $100.3 \mu \mathrm{S} / \mathrm{cm}$ ) compared with the site in Dentergem (altitude of $24 \mathrm{~m}$; pH values of 5.95 and 5.00; EC values of 75.8 and 75.1) which had a texture of loamy sand to sand and an average soil moisture content. The planting in Semmerzake was situated at the southwest of a mature forest. In Dentergem, the planted shrubs were more exposed as the site was located in an agricultural landscape lacking forests, wooded banks, hedges or tree rows that could protect against harsh weathers. As the two planting sites were situated in lowland area very close to each other, no essential mean temperature differences between the sites were expected. We checked this by analysing data from the weather stations nearest to the two common gardens (not on-site) [30]. The average mean yearly temperature between 1980 and 2014 in Semmerzake (weather station at $930 \mathrm{~m}$ from plantation site) was only $0.15^{\circ} \mathrm{C}$ higher than Dentergem (weather station at $1877 \mathrm{~m}$ from plantation site, Figure S1). A paired t-test on the mean monthly temperatures between 1980 and 2014 between the two sites was significant $(\mathrm{df}=12,418, p$ value $<0.001)$. Although significant, the mean temperature difference was considered negligible in terms of influencing factors on the timings of the studied phenophases. The shrubs were planted at both sites with a spacing of $3 \times 3 \mathrm{~m}$ and individually mingled (single tree plot design).

\subsection{Scoring of the Phenophases}

Scoring of the phenophases was performed in 2017. The evolution of the four phenophases, namely, leaf bud burst, flower opening, leaf senescence and leaf fall, was recorded during the different visits to the plantations using four easy-to-use protocols that were specifically composed for this species (Table 2). The recordings were done in both plantations on the same day by the same experienced researcher. For each phenophase, the whole shrub was observed (all buds or leaves were observed), and an average score was given. Leaf bud burst and flower opening were scored on 24 and 30 March and on 6 April 2017 ( 3 observation days for each phenophase). Leaf senescence and fall were scored on 6 and 26 September 2017. For leaf fall, an extra observation day was included on 31 October 2017 ( 2 observation days for leaf senescence, 3 observation days for leaf fall). 
Table 2. Description of the score levels for leaf bud burst, flower opening, leaf senescence and leaf fall.

\begin{tabular}{|c|c|c|}
\hline Phenophase & Score Level & Description \\
\hline \multirow[t]{5}{*}{ bud burst } & 1 & buds closed \\
\hline & 2 & buds opening and first green leaves visible but not yet protruding \\
\hline & 3 & leaves protruding but still folded \\
\hline & 4 & leaves protruded and unfolding \\
\hline & 5 & leaves clearly expanding \\
\hline \multirow[t]{4}{*}{ flower opening } & 1 & flower buds closed \\
\hline & 4 & $\begin{array}{l}\text { inflorescence reaching final length; flowers still closed; angles between inflorescence stalk } \\
\text { and flower stalks enlarged }\end{array}$ \\
\hline & 5 & less than half of the flowers are opening \\
\hline & 6 & more than half of the flowers are opening \\
\hline \multirow[t]{2}{*}{ leaf senescence } & 1 & (nearly) all leaves normal green \\
\hline & 2 & mainly to all leaves light green \\
\hline \multirow{5}{*}{ leaf fall } & 3 & 5 to $25 \%$ of leaf fall \\
\hline & 4 & 25 to $50 \%$ of leaf fall \\
\hline & 5 & 50 to $75 \%$ of leaf fall \\
\hline & 6 & $75 \%$ to $95 \%$ of leaf fall \\
\hline & 7 & all leaves fallen \\
\hline
\end{tabular}

\subsection{Statistical Analysis of Phenological Traits}

All statistical analyses were performed in the open source software R 3.6.1 [31].

Models were fit with each phenological trait $\left(T_{\mathrm{ph}}\right)$ as a response variable. The phenological scorings were in an ordinal scale and therefore modelled using cumulative logistic regression. The function "clmm" in the package ordinal models the probability $(p)$ to have reached maximally a given score level of the response variable [32]. The score levels of bud burst and flower opening were defined in decreasing order, so that the probability to have reached maximally, e.g., a bud burst score of 3, comprised scores 5, 4 and 3. This allowed it to be understood as having reached at least a score of 3 . The score levels for leaf senescence and fall were defined in an increasing order. Mixed models were fit. Location $(L)$, designating the two planting sites Dentergem and Semmerzake, was in the fixed part of each model and accounted for putative deviating responses of the genetic entities at the two different planting sites. A significant location effect pointed therefore to a spatial phenotypic plastic response. Day $(D)$ was also in the fixed part of each model as each phenophase was scored on several days. This variable therefore accounted for the fact that a given plant reached a further development of a given phenophase at a later time of observation. The random part (random intercept) consisted of population $(P)$, genotype $(G)$ and a unique shrub identity $(I D)$. Formula of the applied models:

$$
\log \left(\mathrm{p}_{T \mathrm{ph}} /\left(1-\mathrm{p}_{T \mathrm{ph}}\right)\right)=\alpha_{\mathrm{i}}-\beta_{D} . D(\text { fixed })-\beta_{L} . L(\text { fixed })-\mathrm{r}_{P}(\text { random })-\mathrm{r}_{G}(\text { random })-\mathrm{r}_{I D}(\text { random })
$$

$\alpha_{i}$ is an intercept value between two succeeding score levels. $\beta_{D}$ and $\beta_{L}$ are the estimated coefficients for the fixed covariates $D$ and $L$, respectively. $R_{P}, r_{G}$ and $r_{I D}$ are the random effect coefficients for all the levels of the categorical variables $P, G$ and $I D$, respectively. Variance components attributable to the variation between the populations, further called "interpopulation" $\left(\sigma^{2} p\right)$, between the genotypes within a population, further called "intergenotype" $\left(\sigma_{G}^{2}\right)$ and to the variation within each genotype, which is the variance between ramets of a genotype, further called "intragenotype" $\left(\sigma^{2} I D\right)$ were extracted from the models.

As several ramets per genotype were planted in each common garden, the variance attributable to this component in the models designated the variance due to the micro-environment or to soma-clonal variation, independent of any genetic contribution, whereas intergenotype and interpopulation variance expressed the genetically controlled variation. 
To examine the variability in timing of the four phenophases among the sampled populations, the four models were adjusted by moving the population variable $(P)$ from the random part to the fixed part and by adding an interaction term between population $(P)$ and location $(L)$. Formula of the applied models:

$$
\begin{aligned}
\log \left(\mathrm{p}_{T \mathrm{ph}} /\left(1-\mathrm{p}_{T \mathrm{ph}}\right)\right)=\alpha- & \beta_{D} \cdot D(\text { fixed })-\beta_{L} \cdot L(\text { fixed })-\beta_{P} \cdot P(\text { fixed })-\beta_{L P} \cdot L P(\text { fixed }) \\
& -\mathrm{r}_{G}(\text { random })-\mathrm{r}_{I D}(\text { random })
\end{aligned}
$$

Based on these models, the DOYs (day of the year) were calculated when the probability for having reached at least a bud burst or flower opening score of 4 and having reached a maximally leaf senescence score of 2 and a leaf fall score of 3 attained $50 \%\left(D_{50 \% P}\right)$. A $D_{50 \% P}$ for a given population therefore indicated the day that half of the plants of this population had reached at least (bud burst and flower opening) or maximally (leaf senescence and fall) this stage of the respective phenophase. This calculation was based on the fact that $\log \left(\mathrm{p}_{T \mathrm{ph}} /\left(1-\mathrm{p}_{T \mathrm{ph}}\right)\right)=0$ for $p=50 \%$. For the plantation in Dentergem (Dentergem is the standard level in the model):

$$
D_{50 \% P}=\left(\alpha_{i}-\beta_{P}\right) /\left(\beta_{D}\right)
$$

For the plantation in Semmerzake:

$$
D_{50 \% P}=\left(\alpha_{i}-\beta_{P}-\beta_{L}-\beta_{P L}\right) /\left(\beta_{D}\right)
$$

The formula for Dentergem was adapted for the calculation of $D_{50 \%}$ for each genotype:

$$
D_{50 \% G}=\left(\alpha_{i}-\beta_{P}-r_{G}\right) /\left(\beta_{D}\right)
$$

The genotypic $D_{50 \% G}$ values were used to calculate Pearson correlation coefficients among the four phenophases.

\section{Results}

\subsection{Variance Partitioning between Populations, Genotypes and Ramets}

General linear mixed models were fit to the observational data to examine the timing of the phenophases leaf bud burst, flower opening, leaf senescence and leaf fall in the shrub P. padus in two common gardens (Table 3). The estimated variances of the variables present in the random parts of the models allowed discriminating variance between ramets within genotypes, variance between genotypes within populations and variance between populations. As the location variable was accounted for in the fixed part of the models, results of the variance partitioning were independent of the different growth environments at the two planting sites. Relative interpopulation and intergenotypic variances represented the genetic contributions to the timing of the phenophases, whereas the intragenotypic variance denoted the non-genetic contribution. Among the different phenophases, flower opening displayed the relatively smallest non-genetic contribution (mainly environmentally induced, possibly also soma-clonal variability), and, thus, the relatively highest genetic control, as the intragenotypic variance, was smallest, followed by bud burst and subsequently by leaf senescence and finally leaf fall (Figure 2). The relative interpopulation variance was higher than intergenotypic variance in bud burst, whereas the contributions of these two levels of genetically controlled variances differed relatively less between each other for flower opening, leaf senescence and leaf fall. 
Table 3. Model statistics for the response variables leaf bud burst, flower opening, leaf senescence and leaf fall. Dentergem is the standard level of the variable location to which Semmerzake is compared with. Day is the co-variable indicating the day of observation of the respective phenophase, demonstrating that plants enter further phases of development on later days.

\begin{tabular}{|c|c|c|c|c|c|}
\hline Response Variable & Co-Variable & Estimate & Std. Error & Z Value & $p$ Value \\
\hline \multirow[t]{2}{*}{ bud burst } & Day & -1.33 & 0.105 & -12.72 & $<0.001 * * *$ \\
\hline & Location & -2.35 & 0.467 & -5.04 & $<0.001 * * *$ \\
\hline \multirow[t]{2}{*}{ flower opening } & Day & -1.40 & 0.093 & -15.09 & $<0.001 * * *$ \\
\hline & Location & -0.83 & 0.293 & -2.84 & $0.005 * *$ \\
\hline \multirow[t]{2}{*}{ leaf senescence } & Day & 0.26 & 0.024 & 10.68 & $<0.001 * * *$ \\
\hline & Location & 1.27 & 0.285 & 4.45 & $<0.001 * * *$ \\
\hline \multirow[t]{2}{*}{ leaf fall } & Day & 0.31 & 0.017 & 18.02 & $<0.001 * * *$ \\
\hline & Location & 2.16 & 0.272 & 7.92 & $<0.001 * * *$ \\
\hline
\end{tabular}

Significant results are in bold: ${ }^{* * *} p<0.001 ;{ }^{* *} p<0.01$.
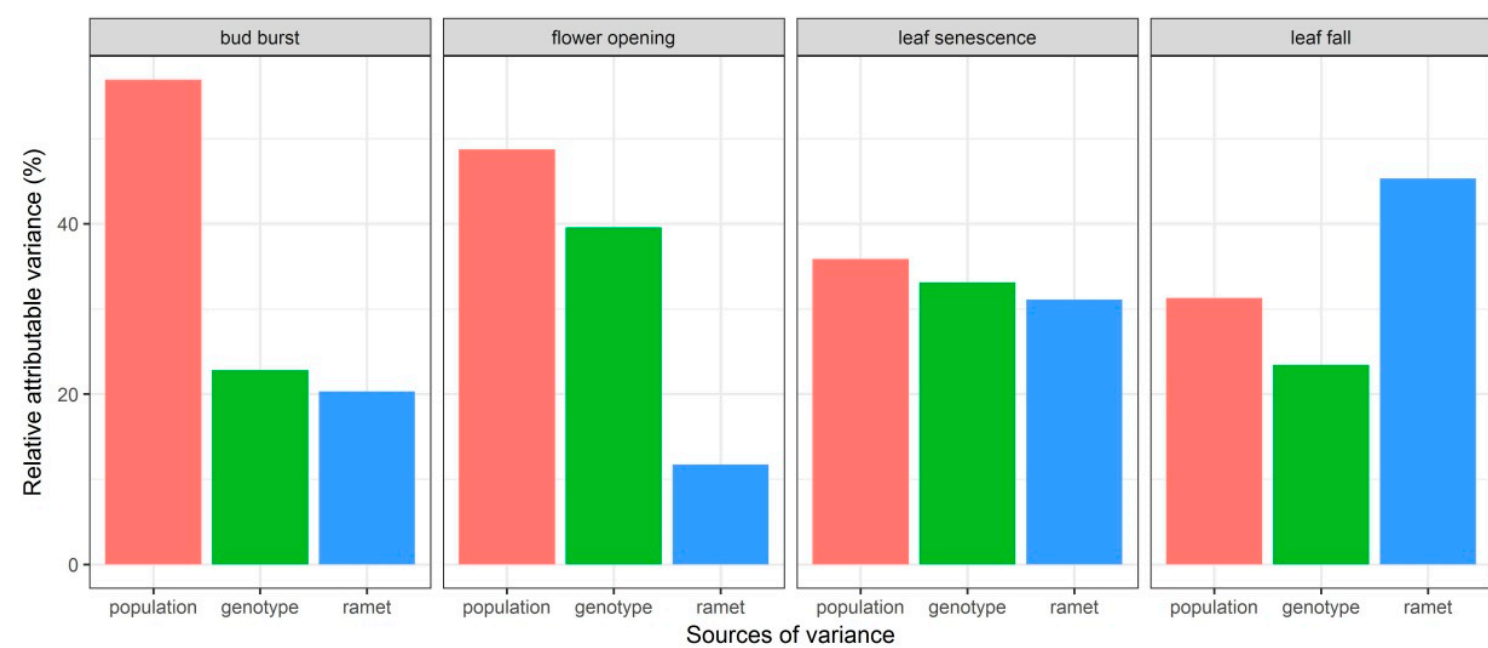

Figure 2. Variance components extracted from the mixed models for the four phenophases observed in the two common gardens. Relative variance is partitioned for populations (between populations), genotypes (between genotypes within populations) and ramets (between ramets within genotypes).

\subsection{Relative Timing of the Phenophases at the Two Planting Sites}

A putative phenotypic plastic response in the phenology of the plants was approached by comparing the responses between the two planting sites. All phenophases showed a significant differentiation in timing between the two studied plantation sites (the variable location being significant in the four models in Table 3: $p$-values $<0,001$ for bud burst, leaf senescence and leaf fall, and $p=0.005$ for flower opening), with shrubs at the more exposed location in Dentergem being delayed in comparison with Semmerzake (Figure 3). As the relative genetic (interpopulation and intergenotypic variance) and the non-genetic (intragenotypic variance) contributions within each location were accounted for in the random parts of the models, a significant location effect represented a different phenotype for the same genotype between the two sites. 

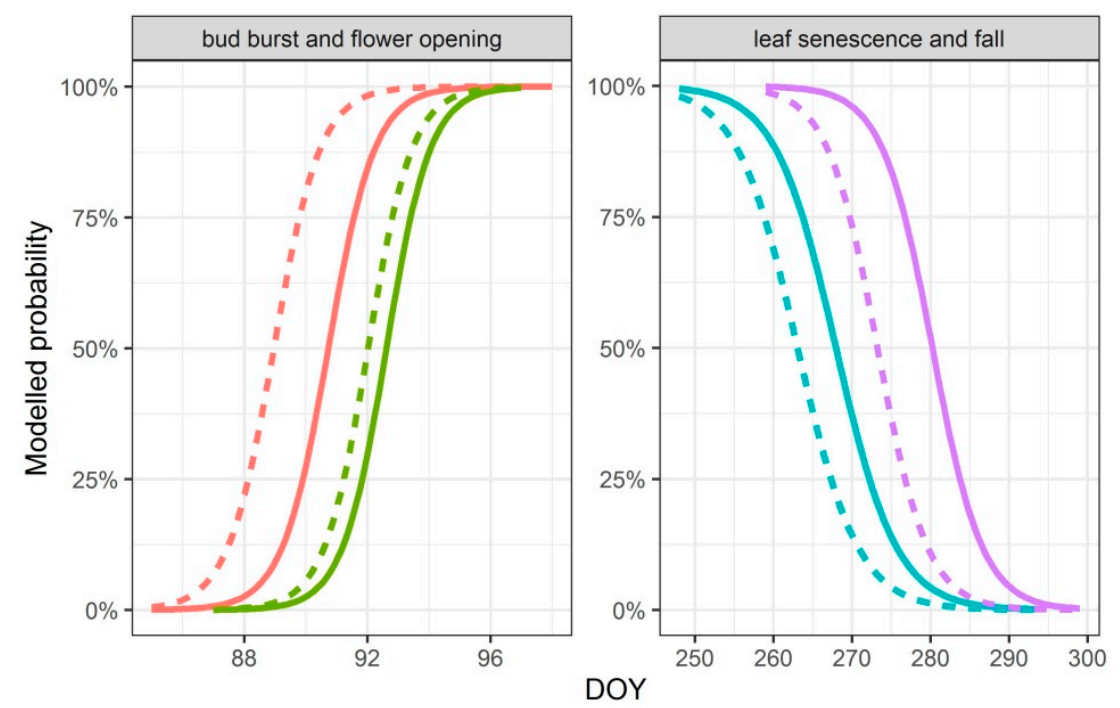

location

- Dentergem

- - Semmerzake

phenophase

- bud burst

- flower opening

- leaf senescence

- leaf fall

Figure 3. Modelled timing of bud burst, flower opening, leaf senescence and leaf fall at the two common gardens Dentergem and Semmerzake. For bud burst and flower opening, the probability is displayed for having reached a score of 4 or higher. For leaf senescence, the probability is displayed for having reached a score of 2 or lower. For leaf fall, the probability is displayed for having reached a score of 3 or lower.

\subsection{Duration and Order in Timing of the Phenophases at the Population and Genotypic Level}

To assess the duration and the order in timing of leaf bud burst, flower opening, leaf senescence and leaf fall at the population and genotypic level, the four phenological models were fit with population as covariate in the fixed part in interaction with the plantation site (Figure S2, Table S1). For each phenophase in each plantation, DOY values were calculated for which each population or genotype had reached the same phenological stage $\left(D_{50 \% P}\right.$ and $D_{50 \% G}$, respectively). For each phenophase, the time span between the two populations with the lowest and the highest $D_{50 \% P}$ were calculated by simple subtractions of the $D_{50 \% P}$ values. Spring phenophases develop more quickly than autumnal phenophases. Flower opening (9.5 days in Dentergem; 9.1 days in Semmerzake) and leaf fall (17.2 days in Dentergem; 22.6 days in Semmerzake) displayed shorter time spans between the first and the last population in comparison with bud burst (14.2 days in Dentergem; 14.8 days in Semmerzake) and leaf senescence (20.4 days in Dentergem; 24.1 days in Semmerzake), respectively. The $D_{50 \% P}$ values were standardized for each phenophase separately and are subsequently shown together in Figure 4 for Dentergem (Figure S3 for Semmerzake). Clearly, the order in timing among the different populations was not maintained across the four phenophases, suggesting deviating influencing factors. Pearson correlation coefficients were calculated between the timing of the different phenophases based on the $D_{50 \% G}$ values (Table 4). As expected, the spring phenophases, bud burst and flower opening, are strongly (and significantly) correlated $(r=0.89)$, as well as the autumnal phenophases, leaf senescence and fall $(r=0.72)$. Bud burst was negatively correlated (significantly) with leaf senescence $(r=-0.38)$, indicating that early flushing genotypes enter leaf senescence later. Flower opening was not correlated with the autumnal phenophases. 


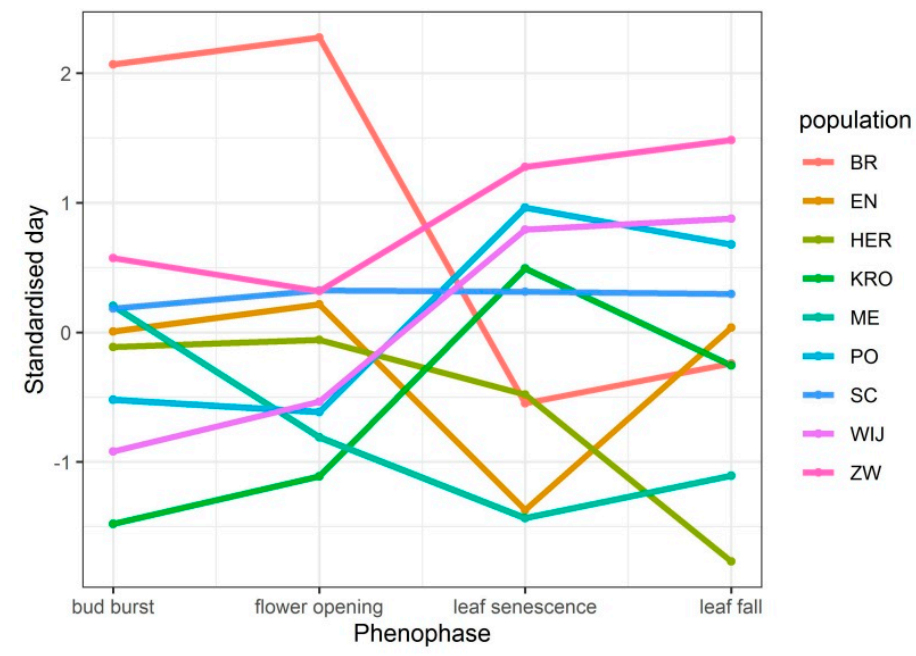

Figure 4. Order of the modelled timing of bud burst, flower opening, leaf senescence and leaf fall for the different sampled populations in the plantation of Dentergem. Standardized days were calculated for which half of the plants of a population had reached a score of 4 or higher (bud burst and flower opening), had reached a score of 2 or lower (leaf senescence) or had reached a score of 3 or lower (leaf fall). Population abbreviations are in Table 1.

Table 4. Pearson correlation coefficients and corresponding $p$ values between the four phenophases (Dentergem).

\begin{tabular}{ccccccc}
\hline & \multicolumn{2}{c}{ Bud Burst } & \multicolumn{2}{c}{ Flower Opening } & \multicolumn{2}{c}{ Leaf Senescence } \\
\hline & $\boldsymbol{r}$ & $\boldsymbol{p}$ Value & $\boldsymbol{r}$ & $\boldsymbol{p}$ Value & $\boldsymbol{R}$ & $\boldsymbol{p}$ Value \\
\hline flower opening & 0.89 & $<\mathbf{0 . 0 0 1} * * *$ & & & & \\
leaf senescence & -0.38 & $\mathbf{0 . 0 0 5 * *}$ & -0.18 & 0.210 & & $<0.001^{* * *}$ \\
leaf fall & -0.20 & $<\mathbf{0 . 1 5 1}$ & -0.002 & 0.991 & 0.72 & $<$ \\
\hline
\end{tabular}

Significant results are in bold: ${ }^{* * *} p<0.001 ; * * p<0.01$.

\section{Discussion}

\subsection{Timing of Leaf Bud Burst and Flower Opening}

The modelling analysis of the seasonal phenophases observed on clonal replicates of P. padus in the two common garden plantations allowed partitioning of the variance attributable to genetic (between populations and between genotypes) and non-genetic (between ramets within genotypes) components, while accounting for the variability attributable to the two planting sites (location in fixed part of the models).

Bud burst displayed the highest interpopulation variation among all phenophases, indicating a relatively higher population differentiation. Population differentiation for bud burst in woody perennials is often encountered in common garden experiments and may be shaped, at least partly, by local adaptation. Habitat fragmentation may also have contributed to the observed population differentiation for bud burst in our study given the fact that Flanders, the northern part of Belgium, is already historically a very densely populated area. Habitat fragmentation affects genetic structures of tree populations including population divergence, as was, for instance, shown for Fagus sylvatica L. [33]. A stronger genetic control for bud burst in comparison with autumnal phenophases may be related to the fact that springtime leafing out modulates the timing of carbon assimilation in deciduous forests more than the autumnal phenophases. Early bud burst was associated with a longer period of carbon uptake and with an increase in net annual carbon fluxes [34]. The gain of 1 day extra photosynthesis in 
spring is more beneficial than an extra day in autumn when days are shorter and trees capture less solar radiation.

In trees, timing of bud burst can be serially auto-correlated with the timing of flowering [14,20], and the control of flowering time has been found to share certain regulations at the molecular level with control of the dormancy/growth cycle [35]. Still, our results indicate some level of deviating control between the timing of the two spring phenophases. Although population differentiation is relatively less high in timing of flowering compared with timing of bud burst, the intergenotypic variance within populations is relatively larger. Together with the larger time span between first and last flowering population compared with bud burst, this may point to a stronger influence of assortative mating. Assortative mating occurs when early flowering plants tend to receive pollen from other early flowering plants, and late flowering plants tend to pollinate later flowering plants, which can be suggested to create larger intergenotypic differences within populations. In a simulation study, already large levels of within-population genetic variation in bud burst were predicted [14], which can be hypothesised to be more accentuated in the timing of flowering, as this phenophase is more directly affected by assortative mating than bud burst. In addition, more diversified flowering phenologies in a population (larger intergenotypic variance) supports the hypothesis that phenological spreading in flowering time reduces the competition for generalist pollinators [36]. Likewise, for herbaceous plants, members of a population rarely flower synchronous [19].

In our study, the timing of flower opening displayed relatively less intragenotypic variance (between ramets) than leaf bud burst, suggesting a lesser sensitivity to environmental variation than leaf bud burst. Two main reasons can be suggested. Firstly, as woody plants only start flowering and fructifying several years after establishment, reproductive phenology only comes under selection after several years, at a time when the most vulnerable seedling phase has passed [37]. In addition, the consequences of a poorly timed flowering, which may result in meagre to absent reproduction, may be less detrimental than poorly timed flushing, which may lead to growth retardation, competitive disadvantages and mortality due to frost exposure [37]. As the penalty for a suboptimal flowering may be less detrimental than for a suboptimal bud burst, selection on timing of flowering may be less stringent than on flushing, even when both occur simultaneously. This may also lead to the relatively lesser population differentiation in timing of flowering observed in this study (bud burst displaying a relatively larger interpopulation variance). Secondly, the putative stronger penalty for a suboptimal bud burst, especially in the vulnerable seedling or sapling stage of a tree or shrub, may have evolved a certain level of plasticity on the individual plant level, which is needed to fine-tune the timing of bud burst to (micro-)environmental conditions. This may have caused the less strong genetic control for timing of bud burst in comparison with flowering in our results (a smaller relative intragenotypic variance-between ramets-for timing of flowering). As plasticity comes at a particular cost [3], the stronger genetic control in timing of flowering may in this sense indicate a lesser need for fine tuning of this timing to (micro-)environmental conditions compared with bud burst. The here described deviations between timing of bud burst and flower opening may be related to the phenomenon described for size variables in plants, with vegetative traits being more sensitive to environmental variation than floral traits [38,39].

\subsection{Timing of Leaf Senescence and Leaf Fall}

In the variance analysis, both leaf senescence and fall express relatively less population differentiation than the spring phenophases. As already mentioned, springtime leafing out modulates the timing of carbon assimilation in deciduous forests more than the autumnal phenophases [34]. The correlation between timing of bud burst and flower opening $(r=0.89)$ is higher than between timing of leaf senescence and fall $(r=0.72)$, although the first is a correlation between the timing of phenophases that take place in different organs (vegetative buds versus generative buds) whereas the latter are expressed consecutively in the same organ (vegetative leaves). This suggests a lesser genetic control for the autumnal phenophases. Both autumnal phenophases display a larger relative 
intragenotypic variance (between ramets), being relatively more pronounced in leaf fall. Although a tight control between the two phenophases is suggested [26], the latter observation suggests a partly deviating control. It can be hypothesised that leaf fall is comparatively more sensitive to other abiotic cues than photoperiod, such as temperature (frost) and wind, leading to slightly more variability at the individual plant level (higher relative intragenotypic variance compared with leaf senescence) as a response to deviating micro-climatic conditions. Nutrient resorption during leaf senescence is not total [40]. Falling leaves retain certain concentrations of nutrients. Our data suggest that a certain level of plasticity at the individual plant level, allowing leaves to retain on the shrub for a longer time in more favourable autumnal conditions, may allow further nutrient reallocation, resulting in a higher nutrient resorption efficiency (the proportion of the nutrients in green leaves prior to senescence that are resorbed before abscission [40]).

\subsection{Variation between the Two Common Gardens}

The negative correlation between timing of bud burst and leaf senescence means that genotypes with an advanced flushing have higher chances on a delayed leaf shedding. These timings thus tend to enlarge or diminish the length of the growing season. A negative correlation between bud burst and leaf colouring has been reported in half sib progenies of P. padus in Sweden [41] and in other species [42]. Conversely, in our experiment, all phenophases are delayed in Dentergem compared with Semmerzake and may, at least partly, be attributed to a phenotypic plastic response to the slightly deviating local growth conditions at the two plantation sites. Probably, the observed phenotypic plasticity, which is in itself also genetically controlled but acts on a shorter time scale in comparison to natural selection, delays or advances all phenophases in response to the local growth conditions in P. padus. The timing of one phenophase influences to a certain extent the timing of the following phenophases in the sense that advancement in spring can create advancement in autumn and so on [22]. It can be hypothesised that natural selection, aiming at enlarging the growing season while minimizing frost risk, can surpass the shorter term legacy effects of phenotypic plastic responses.

\section{Conclusions}

Studies on genetic variation in common gardens of local populations of woody plants are rare. Still, they may help predicting the way populations will react on a changing climate. We investigated the pattern of genetic control and the putative presence of spatial phenotypic plasticity in the seasonal phenophases of the shrub species P. padus planted in two common gardens consisting of local populations. Clearly, the contribution of genetic and non-genetic components to the total variability varied between the four studied seasonal phenophases. We found indications for natural selection in the four phenophases (differentiation at the level of the populations and expansion or contraction of the growing season's length at the level of genotypes). We also found indications for phenotypic plasticity (advancement or delay of all seasonal phenophases between the two plantation sites). These results, based on the variability of only local populations, corroborate the statement that trees harbor capacities for both types of responses to a changing environment.

In addition, we discovered a relatively large intergenotypic variability (within populations) in the timing of flowering, possibly suggesting that not only natural selection but also assortative mating may play a role. Because of the relatively lower intragenotypic variability in flowering time (in comparison with the other phenophases), a lower sensitivity to environmental variation can be hypothesized, so that disturbances may be less detrimental compared with the vegetative seasonal phenologies.

Supplementary Materials: The following are available online at http://www.mdpi.com/1999-4907/11/10/1070/s1, Figure S1: The difference between the mean temperatures in the closest weather stations to the two planting sites of the common gardens in Dentergem and Semmerzake for the period 1980 till 2014. Figure S2: Modelled timing for bud burst (a), flower opening (b), leaf senescence (c) and leaf fall (d) in the common gardens of P. padus for the different sampled local populations. Population abbreviations are in Table 1. Figure S3: Order of modelled timing of bud burst, flower opening, leaf senescence and leaf fall for the different sampled populations in the plantation of Semmerzake. Standardized days were calculated for which half of the plants of a population had 
reached at least (bud burst and flower opening) or maximally (leaf senescence and fall) a given phenological score level. Population abbreviations are in Table 1. Table S1: Model statistics for the response variables bud burst, flower opening, leaf senescence and fall with population as covariate in the fixed parts. Brakel and Dentergem are the standard levels of the variable population and location to which the other levels of the variables (eight other populations and Semmerzake, respectively) are compared with. Population abbreviations are in Table 1.

Author Contributions: The conceptualization of the study was conducted by K.V.M. and S.M. K.V.M. supervised the whole study, while S.M. organized the cuttings and the plant growth in the nursery. S.M. and K.V.M. performed observations in the field. K.V.M. conducted the statistical analyses. K.V.M. and S.M. prepared the manuscript. All authors have read and agreed to the published version of the manuscript.

Funding: This research received no external funding.

Acknowledgments: We are very grateful to all forest rangers that helped with the planting of the Prunus padus plants and that took care of the maintenance of the plantation sites: Jan Pappens, Jean-Pierre Nicaise, Bjorn De Duytsche, Jan Allegaert, Herman Van den Bosch and Yvan Desseyn.

Conflicts of Interest: The authors declare no conflict of interest.

\section{References}

1. Aitken, S.N.; Yeaman, S.; Holliday, J.A.; Wang, T.L.; Curtis-McLane, S. Adaptation, migration or extirpation: Climate change outcomes for tree populations. Evol. Appl. 2008, 1, 95-111. [CrossRef] [PubMed]

2. Nonaka, E.; Svanback, R.; Thibert-Plante, X.; Englund, G.; Brannstrom, A. Mechanisms by which phenotypic plasticity affects adaptive divergence and ecological speciation. Am. Nat. 2015, 186, E126-E143. [CrossRef] [PubMed]

3. Nicotra, A.B.; Atkin, O.K.; Bonser, S.P.; Davidson, A.M.; Finnegan, E.J.; Mathesius, U.; Poot, P.; Purugganan, M.D.; Richards, C.L.; Valladares, F.; et al. Plant phenotypic plasticity in a changing climate. Trends Plant Sci. 2010, 15, 684-692. [CrossRef] [PubMed]

4. Valladares, F.; Gianoli, E.; Gomez, J.M. Ecological limits to plant phenotypic plasticity. New Phytol. 2007, 176, 749-763. [CrossRef]

5. Kremer, A.; Potts, B.M.; Delzon, S. Genetic divergence in forest trees: Understanding the consequences of climate change. Funct. Ecol. 2014, 28, 22-36. [CrossRef]

6. Firmat, C.; Delzon, S.; Louvet, J.M.; Parmentier, J.; Kremer, A. Evolutionary dynamics of the leaf phenological cycle in an oak metapopulation along an elevation gradient. J. Evol. Biol. 2017, 30, 2116-2131. [CrossRef]

7. de Villemereuil, P.; Gaggiotti, O.E.; Mouterde, M.; Till-Bottraud, I. Common garden experiments in the genomic era: New perspectives and opportunities. Heredity 2016, 116, 249-254. [CrossRef]

8. Alberto, F.J.; Aitken, S.N.; Alia, R.; Gonzalez-Martinez, S.C.; Hanninen, H.; Kremer, A.; Lefevre, F.; Lenormand, T.; Yeaman, S.; Whetten, R.; et al. Potential for evolutionary responses to climate change-evidence from tree populations. Glob. Chang. Biol. 2013, 19, 1645-1661. [CrossRef]

9. Gienapp, P.; Merila, J. Disentangling plastic and genetic changes in body mass of siberian jays. J. Evol. Biol. 2014, 27, 1849-1858. [CrossRef]

10. Vitasse, Y.; Lenz, A.; Korner, C. The interaction between freezing tolerance and phenology in temperate deciduous trees. Front Plant Sci. 2014, 5, 541. [CrossRef]

11. Savolainen, O.; Pyhäjärvi, T.; Knürr, T. Gene flow and local adaptation in trees. Annu. Rev. Ecol. Evol. Syst. 2007, 38, 595-619. [CrossRef]

12. Le Corre, V.; Kremer, A. The genetic differentiation at quantitative trait loci under local adaptation. Mol. Ecol. 2012, 21, 1548-1566. [CrossRef] [PubMed]

13. Scotti-Saintagne, C.; Bodenes, C.; Barreneche, T.; Bertocchi, E.; Plomion, C.; Kremer, A. Detection of quantitative trait loci controlling bud burst and height growth in Quercus robur L. Theor. Appl. Genet. 2004, 109, 1648-1659. [CrossRef] [PubMed]

14. Soularue, J.P.; Kremer, A. Assortative mating and gene flow generate clinal phenological variation in trees. BMC Evol. Biol. 2012, 12, 79. [CrossRef]

15. Cornelius, J. Heritabilities and additive genetic coefficients of variation in forest trees. Can. J. For. Res. 1994, 24, 372-379. [CrossRef]

16. Lobo, A.; Hansen, J.K.; Hansen, L.N.; Kjaer, E.D. Differences among six woody perennials native to northern Europe in their level of genetic differentiation and adaptive potential at fine local scale. Ecol. Evol. 2018, 8, 2231-2239. [CrossRef] 
17. Lobo, A.; Hansen, O.K.; Hansen, J.K.; Erichsen, E.O.; Jacobsen, B.; Kjaer, E.D. Local adaptation through genetic differentiation in highly fragmented tilia cordata populations. Ecol. Evol. 2018, 8, 5968-5976. [CrossRef]

18. Jordan, C.Y.; Ally, D.; Hodgins, K.A. When can stress facilitate divergence by altering time to flowering? Ecol. Evol. 2015, 5, S962-S973. [CrossRef]

19. Elzinga, J.A.; Atlan, A.; Biere, A.; Gigord, L.; Weis, A.E.; Bernasconi, G. Time after time: Flowering phenology and biotic interactions. Trends Ecol. Evol. 2007, 22, 432-439. [CrossRef]

20. Soularue, J.P.; Kremer, A. Evolutionary responses of tree phenology to the combined effects of assortative mating, gene flow and divergent selection. Heredity 2014, 113, 485-494. [CrossRef]

21. Nordli, O.; Wielgolaski, F.E.; Bakken, A.K.; Hjeltnes, S.H.; Mage, F.; Sivle, A.; Skre, O. Regional trends for bud burst and flowering of woody plants in norway as related to climate change. Int. J. Biometeorol. 2008, 52, 625-639. [CrossRef] [PubMed]

22. Fu, Y.S.H.; Campioli, M.; Vitasse, Y.; De Boeck, H.J.; Van den Berge, J.; AbdElgawad, H.; Asard, H.; Piao, S.L.; Deckmyn, G.; Janssens, I.A. Variation in leaf flushing date influences autumnal senescence and next year's flushing date in two temperate tree species. Proc. Natl. Acad. Sci. USA 2014, 111, 7355-7360. [CrossRef] [PubMed]

23. Delpierre, N.; Dufrene, E.; Soudani, K.; Ulrich, E.; Cecchini, S.; Boe, J.; Francois, C. Modelling interannual and spatial variability of leaf senescence for three deciduous tree species in France. Agr. For. Meteorol. 2009, 149, 938-948. [CrossRef]

24. Vitasse, Y.; Delzon, S.; Bresson, C.C.; Michalet, R.; Kremer, A. Altitudinal differentiation in growth and phenology among populations of temperate-zone tree species growing in a common garden. Can. J. For. Res. 2009, 39, 1259-1269. [CrossRef]

25. Polgar, C.A.; Primack, R.B. Leaf-out phenology of temperate woody plants: From trees to ecosystems. New Phytol. 2011, 191, 926-941. [CrossRef]

26. Estiarte, M.; Penuelas, J. Alteration of the phenology of leaf senescence and fall in winter deciduous species by climate change: Effects on nutrient proficiency. Global. Chang. Biol. 2015, 21, 1005-1017. [CrossRef]

27. Hegi, G. Illustrierte Flora von Mitteleuropa. Band iv, Teil 2b; Blackwell Wissenschafts Verlag: Berlin, Germany, 1995.

28. Uusitalo, M. European Bird Cherry (Prunus Padus L.)—A Biodiverse Wild Plant for Hortiulture; MTT Agrifood Research Finland: Jokioinen, Finland, 2004.

29. Vander Mijnsbrugge, K.; Cox, K.; Van Slycken, J. Conservation approaches for autochthonous woody plants in Flanders. Silvae Genet. 2005, 54, 197-206. [CrossRef]

30. Delvaux, C.; Journee, M.; Bertrand, C. The forbio climate data set for climate analyses. Adv. Sci. Res. 2015, 12, 103-109. [CrossRef]

31. R_Core_Team. R: A Language and Environment for Statistical Computing; R Foundation for Statistical Computing: Vienna, Austria, 2013; Available online: http://www.R-project.org/ (accessed on 15 April 2019).

32. Christensen, R.H.B. Ordinal: Regression Models for Ordinal Data. R Package Version 2015.6-28. Available online: Http://www.Cran.R-project.Org/package=ordinal/ (accessed on 22 June 2015).

33. Jump, A.S.; Penuelas, J. Genetic effects of chronic habitat fragmentation in a wind-pollinated tree. Proc. Natl. Acad. Sci. USA 2006, 103, 8096-8100. [CrossRef]

34. Churkina, G.; Schimel, D.; Braswell, B.H.; Xiao, X.M. Spatial analysis of growing season length control over net ecosystem exchange. Glob. Chang. Biol. 2005, 11, 1777-1787. [CrossRef]

35. Shim, D.; Ko, J.H.; Kim, W.C.; Wang, Q.J.; Keathley, D.E.; Han, K.H. A molecular framework for seasonal growth-dormancy regulation in perennial plants. Hortic. Res.-Engl. 2014, 1, 1-9. [CrossRef] [PubMed]

36. Bolmgren, K.; Eriksson, O.; Linder, H.P. Contrasting flowering phenology and species richness in abiotically and biotically pollinated angiosperms. Evolution 2003, 57, 2001-2011. [CrossRef]

37. Vander Mijnsbrugge, K.; Onkelinx, T.; De Cuyper, B. Variation in bud burst and flower opening responses of local versus non-local provenances of hawthorn (Crataegus monogyna jacq.) in Belgium. Plant Syst. Evol. 2015, 301, 1171-1179. [CrossRef]

38. Pelabon, C.; Armbruster, W.S.; Hansen, T.F. Experimental evidence for the berg hypothesis: Vegetative traits are more sensitive than pollination traits to environmental variation. Funct. Ecol. 2011, 25, 247-257. [CrossRef]

39. Pelabon, C.; Osler, N.C.; Diekmann, M.; Graae, B.J. Decoupled phenotypic variation between floral and vegetative traits: Distinguishing between developmental and environmental correlations. Ann. Bot.-Lond. 2013, 111, 935-944. [CrossRef] 
40. Aerts, R. Nutrient resorption from senescing leaves of perennials: Are there general patterns? J. Ecol. 1996, 84, 597-608. [CrossRef]

41. Baliuckas, V.; Lagerstrom, T.; Norell, L.; Erksson, G. Genetic variation among and within populations in swedish species of Sorbus aucuparia L. and Prunus padus L. Assessed in a nursery trial. Silvae Genet. 2005, 54, 1-8. [CrossRef]

42. McKown, A.D.; Guy, R.D.; Klapste, J.; Geraldes, A.; Friedmann, M.; Cronk, Q.C.B.; El-Kassaby, Y.A.; Mansfield, S.D.; Douglas, C.J. Geographical and environmental gradients shape phenotypic trait variation and genetic structure in Populus trichocarpa. New Phytol. 2014, 201, 1263-1276. [CrossRef]

(C) 2020 by the authors. Licensee MDPI, Basel, Switzerland. This article is an open access article distributed under the terms and conditions of the Creative Commons Attribution (CC BY) license (http://creativecommons.org/licenses/by/4.0/). 